\title{
Mitos y verdades de estudiar una especialidad
}

\author{
Myths and truths about studying a specialty
}

\begin{abstract}
Angélica Yadira Benítez González, ${ }^{*}$ Claudia Yanín Comparán Bocanegra, ${ }^{*}$ Federico de Jesús Villaseñor de la Isla, ${ }^{*}$ Giovanna Victory Rodríguez, ${ }^{*}$ Gustavo Rodríguez Oliveros, ${ }^{*}$ Javier Alejandro Cornejo Vázquez, ${ }^{*}$ Patricia Alejandra Montiel López ${ }^{*}$
\end{abstract}

Debido a la alta demanda y competencia en todas las áreas laborales del país, son cada vez más las personas que buscan realizar algún postgrado para enriquecer su formación, en este caso en el Área de Ciencias de la Salud, específicamente en Odontología, las especialidades brindan una oportunidad para tener una práctica privada más amplia, adquirir conocimientos más específicos y sentirse más preparado para manejar casos interdisciplinarios. A aquéllos que estén interesados en estudiar una especialidad se les invita a leer este artículo para tener una visión más amplia de lo que es formarse como ESPECIALISTA.

Cuando se plantea la posibilidad de ingresar a una especialidad, lo primero que se sugiere es acercarse a algún especialista para resolver dudas como: ¿cuál fue su experiencia durante su formación?, ¿qué tan difíciles fueron esos años?, ¿̇uánto dinero se requirió?, ¿quiénes y cómo son los maestros que impartirán las clases?, ¿cuánta tarea dejan?, porque son algunas de las cuestiones que surgen al escuchar algunas experiencias y no basta con que sean respondidas una vez, se hacen estas mismas preguntas un sin fin de veces tratando de oír lo que se desea, algo que motive a dar ese paso.

Pero al ir escuchando cada respuesta, sucede que, al contrario de dar valor, comienza a pensarse la situación, pues se está a punto de entrar en un terreno desconocido, lo cual causa temor e incertidumbre; sin embargo, tener la oportunidad de ser especialista es una experiencia única y las ventajas se sobreponen a las posibles complicaciones, por lo cual debe seguirse adelante con esta meta. Una vez dado el primer paso de cumplir los requisitos, siguen los cursos propedéuticos, los cuales pueden desgastar física, mental y emocionalmente, pero las ganas de seguir preparandose motivan a esforzarse sin importar lo difícil que sea la situación.

Después viene la primera gran alegría, muchas veces no sólo personal, es una felicidad tanto de familiares como de amigos; personas que te han visto luchar por ese sueño. Ver tu nombre en la lista de seleccionados, o en otras ocasiones recibir una llamada para felicitarte por ser un nuevo RESIDENTE no tiene comparación (Figura 1). Ya se está ahí, siendo parte de un grupo selecto de personas, algunas veces teniendo que dejar un hogar con ciertas comodidades y privilegios.

Se conoce a nuevas personas, a los compañeros con quienes se pasarán días de felicidad, diversión, pero también de enojo, frustración, nerviosismo y estrés, por lo cual con el tiempo se convierten en equipo, en cómplices y en los mejores aliados, y también a los profesores y guías de quienes se tendrá la oportunidad de adquirir grandes enseñanzas y estarán orientándonos en este camino y, por supuesto, colegas de otras especialidades con los cuales se forma equipo para resolver casos interdisciplinarios.

En cuanto a los mitos y verdades que se escuchan de las especialidades, se tocarán algunos puntos: habrá días en los que esas listas de pendientes, al contrario de ir disminuyendo, aumentan, alimentarse en horarios adecuados o tomar un baño deja de ser prioridad, pues esos minutos son valiosos cuando aún hay tareas por terminar, preparar seminarios clínicos o exposiciones.

Y el dinero se hace rendir, de entrada, el ahorro inicial, con la primera lista de instrumental, equipo y uniformes

\footnotetext{
* Alumno de la generación 2019-2021 de la Especialidad en Periodoncia de la Universidad de Guadalajara. México.
}

Citar como: Benítez GAY, Comparán BCY, Villaseñor IFJ, Victory RG, Rodríguez OG, Cornejo VJA et al. Mitos y verdades de estudiar una especialidad. Rev Mex Periodontol. 2020; 11 (1-3): 4-5. https://dx.doi.org/10.35366/102639 


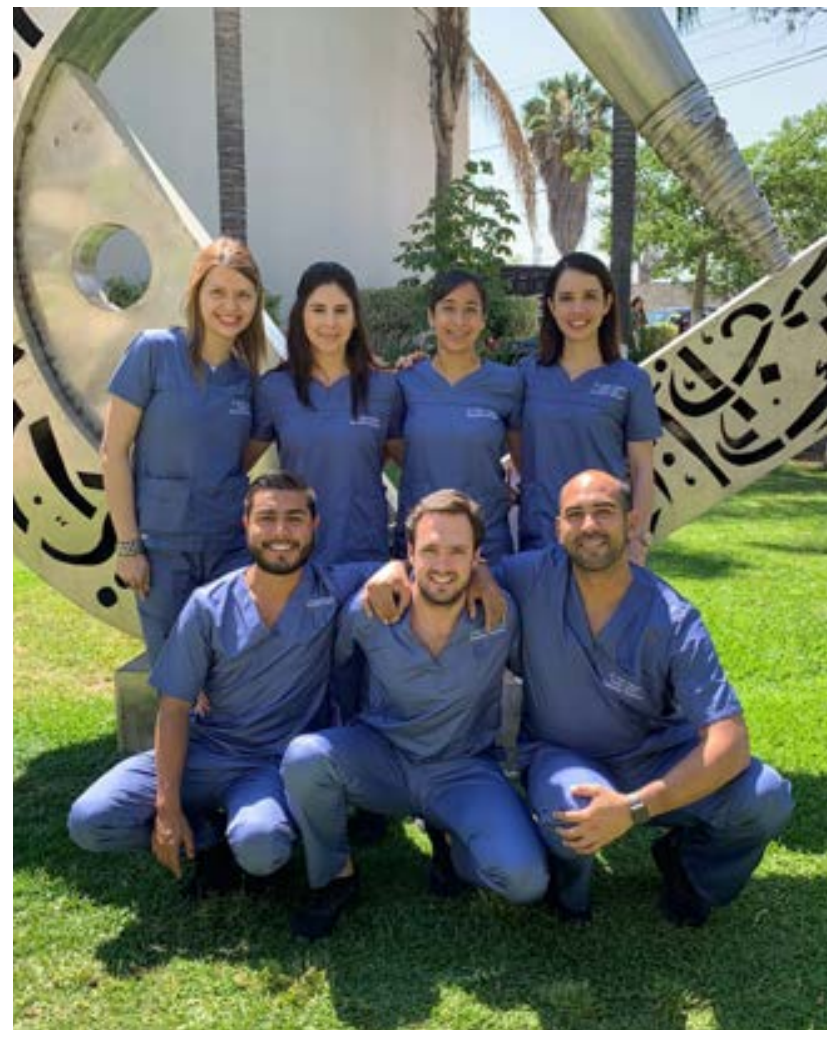

Figura 1: Estudiantes de la Especialidad de Periodontología de la Universidad de Guadalajara, Generación 2019-2021.

prácticamente se acaba. Además, se debe cubrir el pago de la colegiatura. Sin olvidar congresos, cursos, talleres, que algunas veces se confirman en un periodo de tiempo muy corto y no son opcionales, y por lo demandante que es una especialidad en ocasiones no se puede trabajar para generar ingresos, por lo que contar con apoyo extra es una ventaja.

Dentro de la especialidad también se tienen otras oportunidades como irse de intercambios nacionales e internacionales para aprender de otras escuelas, participar en congresos como ponentes o presentando un cartel, y muchas veces se puede obtener un premio, otra razón de satisfacción. Una vez cumplido el periodo de tiempo correspondiente a cada especialidad, se reúnen todos los requisitos para poder titularse, poco a poco esa lista interminable de tareas se empieza a reducir.

Se recupera un poco la vida que se llevaba antes de entrar, pero lo más importante es que se gana una nueva familia que se ha vuelto parte fundamental de este proceso. Ves las caras orgullosas de tus seres amados y uno mismo se llena de dicha al ver que cada pregunta que se tenía al inicio se ha respondido con experiencia propia, que ahora eres ESPECIALISTA, y tienes una visión más amplia del mundo, has crecido en cada sentido de tu vida y se termina esa meta, pero empiezan más porque en cada uno queda hambre de conocimiento, de superación y crecimiento. Los invitamos y animamos a tomar este camino, que si bien tiene sus dificultades y a veces se piensa que no se podrá lograr, claro que es posible, nada se compara con la alegría de haber cumplido la meta de ser especialista y poder servir al mundo con los nuevos y amplios conocimientos adquiridos.

\section{Correspondencia:}

Patricia Alejandra Montiel López

E-mail: patricia.montiel2130@alumnos.udg.mx

\section{www.medigraphic.org.mx}

